\title{
Lymphocyte apoptosis in children with central nervous system tuberculosis: a case control study
}

\author{
Paola Di Carlo ${ }^{1 *}$, Alessandra Casuccio ${ }^{2}$, Amelia Romano $^{3}$, Daria Spicola ${ }^{1}$, Lucina Titone $^{1}$, Nadia Caccamo ${ }^{4}$ \\ Francesco Dieli ${ }^{4}$, Caterina Mammina ${ }^{1}$, Elisabetta Pace ${ }^{5}$, Mark Gjomarkaj $^{5}$, Mario Melis ${ }^{5}$ and Manlio Tolomeo ${ }^{1}$
}

\begin{abstract}
Background: Studies of the apoptosis mechanisms involved in the pathogenesis of tuberculosis have suggested that Mycobacterium tuberculosis can actively interfere with the apoptosis of infected cells. In vivo studies have been performed in adult populations but have not focused on this process in children. In the present study, we analyzed spontaneous T lymphocyte (PBT) apoptosis in the peripheral blood of children with central nervous system tuberculosis (CNS TB), before and after chemotherapy, and compared the results with healthy controls.

Methods: A case-control study was conducted from January 2002 to June 2009. It included 18 children with CNS $\mathrm{TB}$ and 17 healthy controls. Spontaneous apoptosis of PBTs, including $\mathrm{CD}^{+}, \mathrm{CD} 8^{+}$and $\mathrm{CD} 8^{+} / \mathrm{CD} 28^{+} \mathrm{T}$ cells, was evaluated after 24 and $72 \mathrm{~h}$ of culture in complete medium, using the Annexin V detection test. Analysis was conducted before and after chemotherapy, and expression of the apoptotic markers CD95 (Fas) and Fas ligand (FasL) was evaluated.
\end{abstract}

Results: Higher percentages of apoptotic T cells and CD4 lymphocytes were isolated from children with acute phase CNS TB than from children in the control group $(p<0.05)$. This difference significantly decreased after 60 days of specific treatment. In children with CNS TB, high levels of Fas ligand expression were detected in lymphocyte populations, associated with a high percentage of Fas positive cells, before and after treatment. In contrast to the CD4+ apoptosis profile, we did not find any significant difference in total $\mathrm{CD} 8^{+}$cell apoptosis between children with acute phase disease and the control group. However, the percentage of apoptotic $\mathrm{CD} 8^{+} / \mathrm{CD} 28^{+} \mathrm{T}$ cells was significantly higher in the children with acute phase disease than in the healthy controls.

Conclusions: Our findings indicate that CNS TB in pediatric patients increases the sensitivity of $C D 4$ and $C D 8^{+} / C D 28^{+} T$ cells to apoptosis, suggesting a hypoergic status of this infection. This could play a key role in the immunopathogenesis of this complicated form of TB. Interestingly, specific chemotherapy is able to normalize both apoptosis sensitivity and T-cell activation.

\section{Background}

Pediatric tuberculosis (TB) remains one of the most important communicable diseases and represents a major health problem in the developing world. Globally, approximately 1 million new cases and approximately 500,000 deaths due to pediatric TB are reported every year $[1,2]$.

In Italy, similar to many other industrialized nations, $\mathrm{TB}$ is a relatively rare disease. In the last few years, the incidence of TB has been less than 10 cases/100,000

\footnotetext{
* Correspondence: paola.dicarlo@unipa.it

'Department of Sciences for Health Promotion, University of Palermo, Via del Vespro 133, Palermo 1-90127, Italy

Full list of author information is available at the end of the article
}

population (in 2009 the rate was $7 / 100,000$ population, corresponding to just over 4,200 cases) while according to WHO estimates, the prevalence of latent infections is $12 \%$ (corresponding to just over 7,200,000 latent infections) [1].

While $90 \%$ of immunocompetent adult patients infected by the tubercle bacillus will not develop the disease during their lifetime, children have shown various clinical forms of infection and progressive disease [2,3]. Although pulmonary TB tends to be the most common form of $\mathrm{TB}, \mathrm{TB}$ of the central nervous system (CNS) carries the highest mortality and morbidity rates and develops in $4 \%$ of infected children, especially during infancy [4-6].

\section{Biomed Central}


It is well known that the immune system of a child is too immature to stimulate a host protective response against intracellular pathogen growth. Some progress towards understanding the mechanism involved in immune responses to Mycobacterium tuberculosis infection has been made by studying adult patients. However, other aspects need to be assessed through research in pediatric populations. The relevant role of apoptosis (programmed cell death) in the development of the immune system in children has recently been highlighted in studies on the efficacy of the TB vaccine $[7,8]$.

Recent studies have demonstrated that $M$. tuberculosis actively interferes with the apoptosis of infected cells in vitro as a means of virulence, and that dysregulation of the host's lipid metabolism is a major pathway for generating pathology and promoting necrosis over apoptosis $[9,10]$. However, the importance of apoptosis as a virulence mechanism in vivo and interaction of apoptotic mechanisms with the host cytokine response have been largely unexplored until recently, with this area of research slowly being understood [10-12].

A number of alternative mechanisms of peripheral $\mathrm{T}$ cell apoptosis have been defined. The distinction has been made between active apoptosis, which follows stimulation and activation of the T cells, and passive apoptosis, which occurs as a result of withdrawal of the sustaining cytokines following activation [13-16]. Activation of death receptors by their ligands can initiate apoptosis. Fas and Tumor Necrosis Factor (TNF) receptors are more clearly understood than others, and their important role in peripheral $\mathrm{T}$ cell apoptosis has been demonstrated. The Fas/Fas ligand (FasL) interaction is particularly important in initiating activation induced cell death of CD4 ${ }^{+} \mathrm{T}$ cells [17-20].

Understanding the specific mechanisms by which children's T cells fail to contain Mycobacterium TB infection could offer potential new targets for appropriate vaccines. In addition, studying the defects in infant immune responses that explain poor bacterial control may contribute more broadly to our understanding of severe forms of TB such as CNS TB.

In this study, we analyzed spontaneous $\mathrm{T}$ lymphocyte (PBT) apoptosis and the subsets CD3+, CD4+ and CD8+, including the analysis of apoptotic $\mathrm{CD}^{+} / \mathrm{CD} 28^{+} \mathrm{T}$ cells, in the peripheral blood of children with CNS TB, before and after starting anti tubercular treatment and compared them with healthy control children.

\section{Methods}

\section{Subjects}

Eighteen children with CNS TB (10 boys, 8 girls; mean age [ \pm SD], 3.8 years [3.4]; range, $0.5-12$ years] admitted to the G. Di Cristina Children's Hospital in Palermo, Italy, were selected according to Centers for Disease Control (CDC)
Case Definition clinical and/or microbiological criteria between January 2002 and December 2009 [21].

Diagnosis was bacteriologically confirmed by polymerase chain reaction (PCR) and/or culture of $M$. tuberculosis complex in CSF samples and/or CSF culture, as previously reported [22,23]. CSF culture and PCR were positive in $60 \%$ and $90 \%$ of patients, respectively. Resistant strains to 1 or more anti-TB drugs were found in 4 children and their adult sources.

Seven patients (38\%) had pulmonary TB. The source of infection was documented for 9 patients (50\%): it was grandparents for 4 patients, parents for 3 patients, a teacher for 1 patient, and a neighbor for 1 patient.

All of the children received antitubercular treatment for 1 year, consisting of 2 months of isoniazid (INH), rifampicin (RMP), pyrazinamide (PZA) and streptomycin (SM) or ethambutol (ETB), followed by 10 months of RMP and INH [24].

All the subjects enrolled in the study were negative for human immunodeficiency virus (HIV).

A control group comprised 17 healthy children who were Purified Protein Derivative (PPD) skin test negative (10 boys and 7 girls; mean age [ \pm SD], 5.6 years [3.2]; range, 2-12 years). The study protocol was approved by the Ethics Committee of the G. Di Cristina Hospital in Palermo (Italy) and informed consent was sought in accordance with the principles of the Declaration of Helsinki. Patients were thoroughly informed about the procedures and written informed consent was obtained from each of them. Peripheral blood was drawn from children with CNS TB during the acute phase of illness, and 30-60 days and 90 days after starting chemotherapy. The follow-up time point after the start of antitubercular therapy was chosen on the basis of previous studies conducted by our group $[22,25,26]$.

\section{Isolation of peripheral blood mononuclear cells (PBMCs)} PBMCs were isolated by Ficoll-Paque density centrifugation from $20 \mathrm{~mL}$ of heparinized blood drawn from children with CNS-TB and from the healthy children in the control group.

PBMC cultures: PBMCs were cultured in RPMI 1640 medium supplemented with $10 \% \mathrm{FCS}$ at $37^{\circ} \mathrm{C}$ in a humidified atmosphere of $5 \% \mathrm{CO}_{2}[27,28]$.

\section{Apoptosis detection and PBT phenotype analysis}

$\mathrm{T}$ cell spontaneous apoptosis was determined after 24 and $72 \mathrm{~h}$ of culture in complete medium, using the Annexin V detection kit as previously described [27,28]. Apoptotic cells were identified by means of double or triple staining with an Annexin V-FITC kit (Bender MedSystem, Vienna, Austria) and anti-human peridinin chlorophyll proteinCD3 (Becton Dickinson, San Jose, CA, USA), and anti- 
human phycoerythrin (RPE)-conjugated CD8 (Dakopatts, Glostrup, Denmark) or anti-human RPE-conjugated CD4 clone MT310 (Dakopatts). T lymphocytes were also investigated for their expression of CD28 (Dakopatts). Cell apoptosis and the phenotype of PBTs were determined with a FACSCalibur Plus flow cytometer (Becton Dickinson). Phycoerythrin-conjugated (X-928, Dakopatts) and FITC-conjugated mouse anti-human IgG1 (X-927, Dakopatts) were used as negative controls.

\section{Fas and Fas-L expression}

Fas and FasL expression were evaluated by flow cytometry (Becton Dickinson) using antihuman PE-conjugated CD95 and antihuman FITC conjugated CD95L (Dakopatts) MoAbs. PE-conjugated (X-928, Dakopatts) and FITC-conjugated mouse antihuman IgG1 (X-927, Dakopatts) were used as negative controls. Fas and FasL expressions are shown as the percentage of positive cells.

\section{Statistical analysis}

Discrete variables were analyzed using the chi-square and Fisher's exact tests, as needed. The independent Student's t test and the Mann-Whitney U statistic test were used for parametric and non-parametric analysis, respectively. The paired-samples Student's t-test and paired Wilcoxon signed-rank test were used for intragroup parametric and non-parametric analysis, respectively. All statistical tests were two-tailed and were applied at the $5 \%$ significance level. Data were analyzed with Epi Info software, version 3.2.2 (Centers for Disease Control and Prevention, Atlanta, Georgia, USA) and SPSS software (version 14.0; SPSS Inc., Chicago, IL, USA).

\section{Results}

\section{T lymphocytes, Fas and FasL during CNS TB}

The mean $( \pm \mathrm{SD})$ total lymphocyte and $\mathrm{CD}^{+}$lymphocyte counts in peripheral blood of patients in the acute phase of disease and in controls are shown in Table 1. There were no significant differences between the 2 groups $(\mathrm{p}>0.05)$.

Spontaneous apoptosis of PBTs isolated from CNS TB patients and from the healthy controls was evident after $24 \mathrm{~h}(\mathrm{p}<0.0005)$, and steadily increased after $72 \mathrm{~h}(\mathrm{p}<$ $0.0005)$.

Table 1 Peripheral blood lymphocyte populations* in acute CNS TB children and uninfected children (controls)

\begin{tabular}{lccc}
\hline & Acute phase & Controls & P-value \\
\hline Lymphocytes $\left(\times 10^{9} / \mathrm{l}\right)$ & $6.77(3.6)$ & $6.58(2.8)$ & 0.863 \\
CD3+ T -lymphocytes $\left(\times 10^{9} / \mathrm{l}\right)$ & $6.20(3.2)$ & $5.11(2.1)$ & 0.245 \\
CD4+ T -lymphocytes $\left(\times 10^{9} / \mathrm{l}\right)$ & $2.17(1.2)$ & $2.28(0.8)$ & 0.753 \\
CD8+ T -lymphocytes $\left(\times 10^{9} / \mathrm{l}\right)$ & $1.33(0.6)$ & $1.09(0.4)$ & 0.176 \\
CD28+ T -lymphocytes $\left(\times 10^{9} / \mathrm{l}\right)$ & $0.36(0.2)$ & $0.27(0.1)$ & 0.105 \\
\hline
\end{tabular}

* mean values $( \pm \mathrm{SD})$
There was a significant increase in apoptotic $\mathrm{CD} 3^{+}$ lymphocytes in the children with acute phase CNS TB after $24(\mathrm{p}<0.0005)$ and $72 \mathrm{~h}$ of incubation compared with those in the control group $(p<0.0005)$. This increased sensitivity in $\mathrm{CD}^{+}$lymphocytes to apoptosis was still evident after 30-60 days of specific anti-tubercular therapy, but it was decreased in children treated for more than 90 days (Figure 1).

Fas and FasL expression was significantly higher in the $\mathrm{T}$ lymphocytes of children with acute phase CNS TB than that in healthy control group children after 24 and $72 \mathrm{~h}$ of incubation $(\mathrm{p}<0.0005$, Figure $2 \mathrm{a}, \mathrm{b})$. This difference was still evident in patients treated for 30-60 days (Fas and FasL after 24 h, p = 0.010, p < 0.0005; Fas and FasL after 72 h, p $<0.0005, \mathrm{p}<0.0005)$, but it was decreased in children treated for more than 90 days (Fas and FasL after 24 h of incubation, p > 0.05, p = 0.024; Fas and FasL after $72 \mathrm{~h}$ of incubation, $\mathrm{p}=0.003, \mathrm{p}=$ 0.025 ; Figure $2 \mathrm{a}, \mathrm{b})$.

\section{T Lymphocyte subset apoptosis during CNS TB}

The mean $( \pm \mathrm{SD}) \mathrm{CD}^{+}, \mathrm{CD}^{+}$and $\mathrm{CD}^{+} / \mathrm{CD} 28^{+} \mathrm{T}$ lymphocyte counts in patients during the acute phase of the disease and in the controls are shown in Table 1. There were no significant differences between the 2 groups ( $\mathrm{p}>0.05)$.

Spontaneous apoptosis was evaluated in different $\mathrm{CD}^{+}$ lymphocyte subpopulations $\left(\mathrm{CD} 4^{+}, \mathrm{CD}^{+}\right)$of patients affected by CNS TB and in children in the control group.

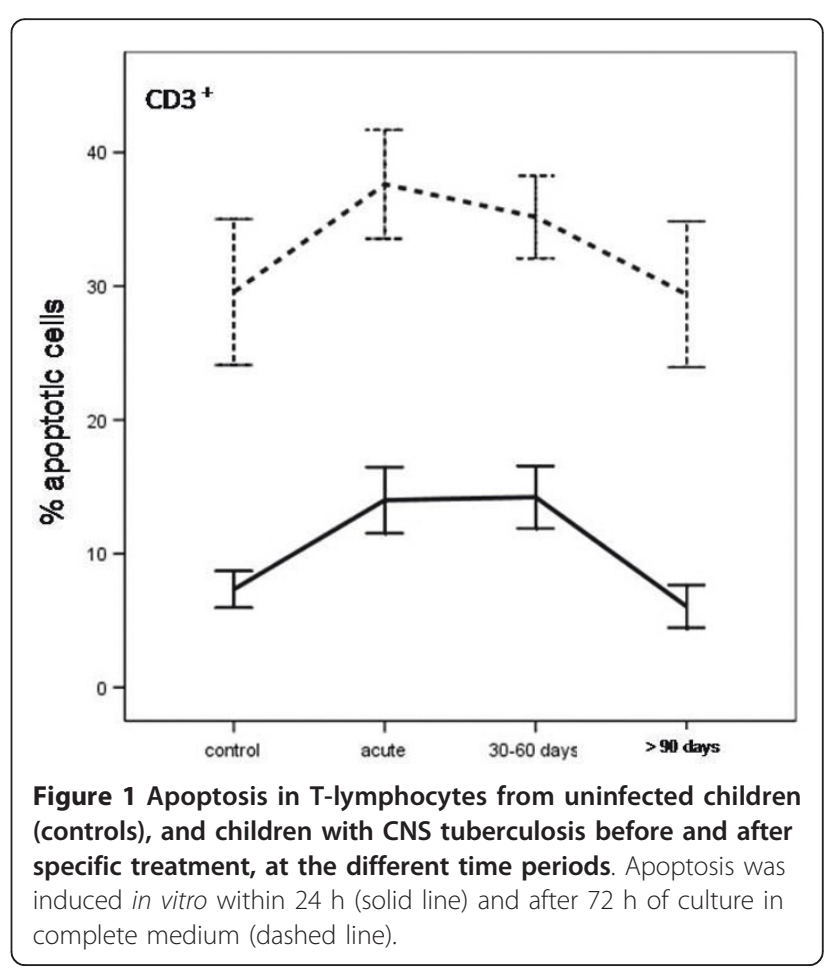



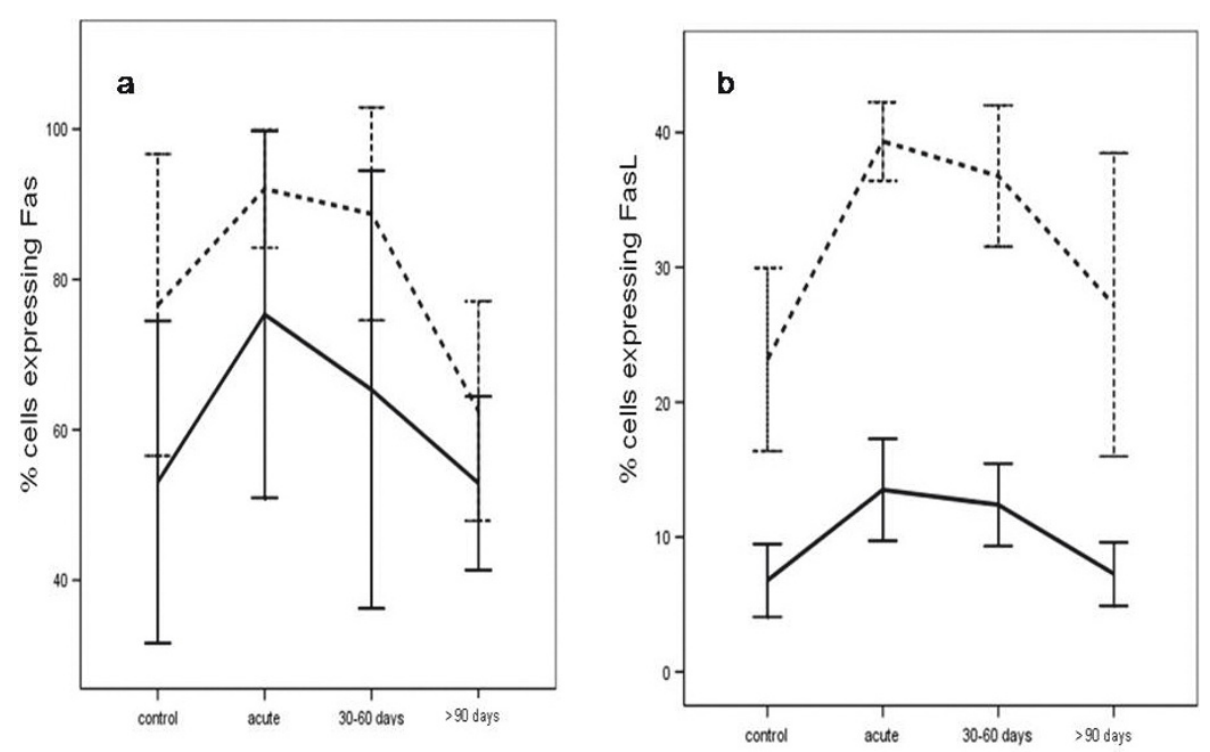

Figure 2 Fas (2a) and FasL (2b) expression during central nervous system tuberculosis in the illness group, before and after specific treatment at the different time periods, and in uninfected children (controls). Results are shown as percentage of Fas and FasL -expressing cells among T-lymphocytes after $24 \mathrm{~h}$ (solid line) or within $72 \mathrm{~h}$ of culture in complete medium (dashed line).

As shown in Figure 3, only CD4 ${ }^{+}$T-lymphocytes isolated from the TB children before treatment showed a greater sensitivity towards apoptosis than those of the control group (acute vs control after 24 and $72 \mathrm{~h}$ of incubation, $\mathrm{p}=0.019$ and $\mathrm{p}<0.0005$, respectively). This difference was decreased after 30-60 days of antitubercular treatment

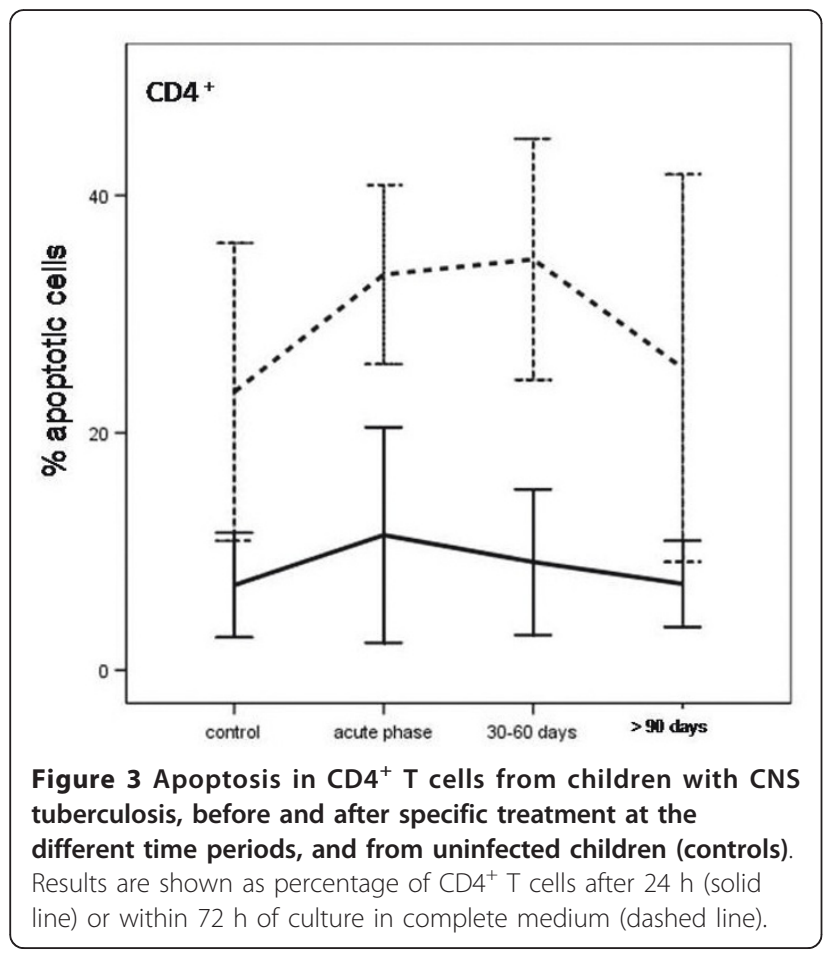

(after 24 and $72 \mathrm{~h}$ of incubation, $\mathrm{p}=0.027$ and $\mathrm{p}=0.035$, respectively) and disappeared after 90 days (acute vs control after 24 and $72 \mathrm{~h}$ of incubation, $\mathrm{p}>0.05$ ).

Comparative analysis of apoptosis in $\mathrm{CD}^{+}$lymphocyte populations in acute phase CNS TB children treated for 30-60 days and for more than 90 days and in the controls showed no significant differences after 24 and $72 \mathrm{~h}$ of incubation $(\mathrm{p}>0.05)$.

Analysis of apoptotic $\mathrm{CD} 8^{+} / \mathrm{CD} 28^{+} \mathrm{T}$ cells showed impaired cell apoptosis in the acute phase of disease (acute vs control after 24 and $72 \mathrm{~h}$ of incubation, $\mathrm{p}<$ 0.0005 and $p=0.002$, respectively). The difference between CNS TB patients and healthy control children decreased after 90 days of specific treatment $(\mathrm{p}>0.05$, Figure 4).

\section{Discussion}

The results of our study show that PBTs isolated from children with CNS TB had a stronger apoptotic response and underwent apoptosis more rapidly than those of healthy subjects, even after 3 months of antitubercular treatment. These responses were due to high levels of FaL expression in lymphocyte populations. Moreover, the number of Fas positive cells remained high even after starting treatment for TB. The reason for these findings may be because Koch's bacillus produces or induces substances in macrophages that increase the sensitivity of lymphocytes to apoptosis by increasing Fas expression or Fas-L for protection against antitubercular activity $[9,29]$.

We did not find any significant difference in the absolute number of $\mathrm{T}$ lymphocytes and their subsets in the 


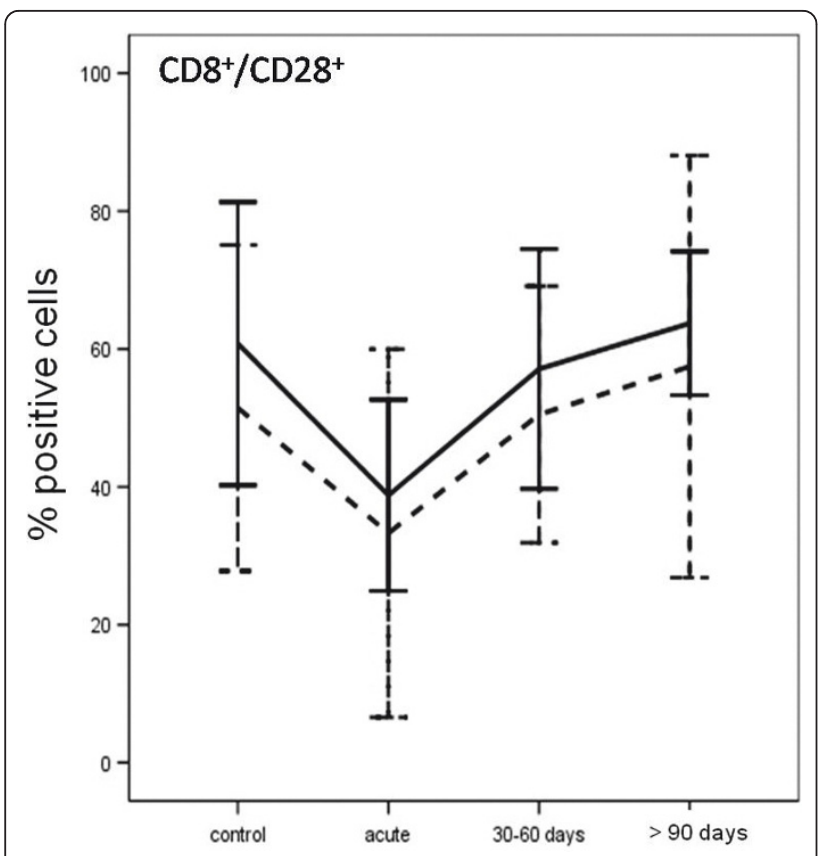

Figure 4 Percentage of $\mathrm{CD}^{+} / \mathrm{CD} 28^{+} \mathrm{T}$ from children with $\mathrm{CNS}$ tuberculosis, before and after specific treatment at the different time periods, and from uninfected children (controls). Results are shown as percentage of $\mathrm{CD}^{+} / \mathrm{CD}^{2} 8^{+} \mathrm{T}$ cells after $24 \mathrm{~h}$ (solid line) or within $72 \mathrm{~h}$ of culture in complete medium (dashed line).

peripheral blood in children with CNS TB and healthy controls. A previous study of adult pulmonary TB patients showed a significantly lower percentage of $\mathrm{CD}^{+}$and $\mathrm{CD} 4^{+}$cells, and a significantly lower ratio of $\mathrm{CD} 4^{+}$and $\mathrm{CD} 8^{+}$cells compared with healthy controls [30].

$\mathrm{CD} 4^{+}$cells are critical in immunity against $M$. tuberculosis infection. CD4+ T lymphocytes play 2 important roles in TB infection: first, they produce cytokines that govern cell-mediated immune responses; and second, they eliminate infected macrophages via apoptosis [31-33].

The relevant role of $\mathrm{CD} 4^{+}$cells in the pathogenesis of CNS TB is confirmed by $\mathrm{CD} 4^{+}$cell counts and TB meningitis in the HIV population [33]. We observed a high percentage of $\mathrm{CD}^{+} \mathrm{T}$ lymphocyte apoptosis in our study population, both in the acute phase of disease and after the start of specific treatment. Therefore, CD4 depletion by apoptosis is a foreseeable phenomenon in TB patients. In fact, we found that patients with a more severe form of $\mathrm{TB}$ had $\mathrm{CD} 4^{+}$lymphocyte depletion despite their $\mathrm{CD} 4^{+}$ cell counts. In contrast to the $\mathrm{CD} 4^{+}$apoptosis profile, we did not find any significant difference in $\mathrm{CD}^{+}$cell apoptosis between children with CNS TB and the control group. This could be the consequence of increased $\mathrm{CD} 4^{+}$lymphocyte apoptosis through the Fas/FasL system.

$\mathrm{CD}^{+} \mathrm{T}$ cells can efficiently eradicate $\mathrm{TB}$ infection by inducing apoptosis of infected cells, and this cell death is mainly, but not always, mediated via the Tumor Necrosis Factor Receptors (TNFR) [17,34,35]. The hypoergic status of CD8 T cells and the increased susceptibility of CD4 $\mathrm{T}$ cells to apoptosis may be induced by specific cytokines produced during infection to avoid an immunological response against Koch's bacillus $[14,35]$. Although different $M$. tuberculosis specific CD8 ${ }^{+} \mathrm{T}$ cell subsets, such as $\mathrm{CD} 27^{+}$and $\mathrm{CD} 28^{+}$(activated $\mathrm{T}$ cells), may be involved in these mechanisms, their role is not well understood in pediatric patients $[31,36]$.

Interestingly, $\mathrm{CD}^{+} / \mathrm{CD} 28^{+} \mathrm{T}$ cell apoptosis was significantly lower in the children with CNS TB before chemotherapy, suggesting a protective role of these cells in response to $M$. tuberculosis infection. Contrasting results have been reported in other studies. Both increases and decreases in levels of $\mathrm{CD}^{+} / \mathrm{CD} 28^{+} \mathrm{T}$ cells in peripheral blood have been detected in adult patients with active TB compared with healthy controls [36,37]. However, further studies are required to elucidate the mechanisms of these phenomena.

Our study suggests that TB infection in children increases the sensitivity of $\mathrm{CD} 4^{+} \mathrm{T}$ lymphocytes to apoptosis and causes a decrease in $\mathrm{CD}^{+}$activated $\mathrm{T}$ lymphocytes. Interestingly, chemotherapy was able to normalize both apoptosis sensitivity and $\mathrm{T}$ cell activation. This could play a key role in the immune pathogenesis of the disease. Involvement of the CNS is a serious complication of TB and is most frequent in children aged between 6 months and 6 years, although it can occur at any age $[4,5]$. Ten of the children in our study population were in this age range. Consequently, our data may help the understanding of what type of immune response against the tubercle bacillus is activated in the first year of life.

\section{Conclusions}

To our knowledge, this is the only study to date to evaluate apoptosis in $\mathrm{T}$ lymphocytes from children with CNS TB. A better understanding of apoptosis regulation in TB is required to develop new immune-based therapies aimed at modulating apoptosis in infected patients. Considering the current, very poor laboratory support for the diagnosis and management of childhood TB, further studies with large numbers of subjects are required to define the clinical value of these assays.

\section{List of abbreviations}

FACS: Fluorescence Activated Cell Sorting; CD: Cluster differentiation; FITC: fluorescein- isothiocyanate; PE: phycoerythrin.

\section{Author details}

'Department of Sciences for Health Promotion, University of Palermo, Via del Vespro 133, Palermo 1-90127, Italy. ${ }^{2}$ Department of Experimental Biomedicine and Clinical Neuroscience, University of Palermo, Via del Vespro 133, Palermo I-90127, Italy. ${ }^{3}$ Pediatric Infectious Diseases, G. Di Cristina Children's Hospital, ARNAS Civico, P.zza Montalto, 8, Palermo 1-90157, Italy. ${ }^{\text {DDepartment of }}$ Biopathology, University of Palermo, Corso Tukory 211, Palermo I- 90134, 
Italy. ${ }^{5}$ CNR Institute of Biomedicine and Molecular Immunology, Via Ugo La Malfa 153, Palermo 1-90146, Italy.

\section{Authors' contributions}

PD designed the study and drafted the manuscript. NC, FD, BP, DS and MG set up and conducted the study in the field and contributed to the interpretations of results. MM and MT were responsible for laboratory analysis. AC was responsible for the acquisition, statistical analysis and interpretation of data. The ethics application and funding applications were submitted by PD, AR and LT as the principal pediatric investigators. MC provided microbiological data. MT supported apoptosis laboratory results, supervised the study and revised the manuscript. All authors have read and approved the final manuscript.

\section{Competing interests}

The authors declare that they have no competing interests.

Received: 6 August 2011 Accepted: 23 November 2011 Published: 23 November 2011

\section{References}

1. WHO: Global tuberculosis control 2010. WHO Report 2010.

2. UNICEF: The state of the World's children. Unicef Main Report 2011

3. Newton SM, Brent AJ, Anderson S, Whittaker E, Kampmann B: Paediatric tuberculosis. Lancet Infect Dis 2008, 8:498-510.

4. Swaminathan S, Rekha B: Pediatric tuberculosis: global overview and challenges. Clin Infect Dis 2010, 50:184-194.

5. Garg RK: Tuberculosis of the central nervous system. Postgrad Med J 1999, 75:133-140

6. Be NA, Kim KS, Bishai WR, Jain SK: Pathogenesis of central nervous system tuberculosis. Curr Mol Med 2009, 9:94-99.

7. Hanekom WA: The immune response to BCG vaccination of newborns. Ann N Y Acad Sci 2005, 1062:69-78.

8. Soares AP, Scriba TJ, Joseph S, Harbacheuski R, Murray RA, Gelderbloem SJ, Hawkridge A, Hussey GD, Maecker H, Kaplan G, Hanekom WA: Bacillus Calmette-Guérin vaccination of human newborns induces $T$ cells with complex cytokine and phenotypic profiles. J Immunol 2008, 1:3569-3577.

9. Mustafa T, Bjune TG, Jonsson R, Pando RH, Nilsen R: Increased expression of fas ligand in human tuberculosis and leprosy lesions: a potential novel mechanism of immune evasion in mycobacterial infection. Scand J Immunol 2001, 54:630-639.

10. Briken V, Miller JL: Living on the edge: inhibition of host cell apoptosis by Mycobacterium tuberculosis. Future Microbiol 2008, 3:415-422.

11. Abebe $M$, Kim L, Rook G, Aseffa A, Wassie L, Zewdie M, Zumla A, Engers $H$, Andersen P, Doherty TM: Modulation of cell death by M. tuberculosis as a strategy for pathogen survival. Clin Dev Immunol 2011, 2011:678570, Epub 2011 Jan 4.

12. Behar SM, Divangahi M, Remold HG: Evasion of innate immunity by mycobacterium tuberculosis: is death an exit strategy? Nat Rev Microbiol 2010, 8:668-674

13. Boom WH, Wallis RS, Chervenak KA: Human Mycobacterium tuberculosisreactiveCD4+ T-cell clones: heterogeneity in antigen recognition, cytokine production, and cytotoxicity for mononuclear phagocytes. Infect Immun 1991, 59:2737-2743.

14. Dubaniewicz A, Trzonkowski P, Dubaniewicz-Wybieralska M, Dubaniewicz A, Singh M, Myśliwski A: Mycobacterial heat shock protein-induced blood T lymphocytes subsets and cytokine pattern: comparison of sarcoidosis with tuberculosis and healthy controls. Respirology 2007, 12:346-354.

15. Arcila ML, Sánchez MD, Ortiz B, Barrera LF, García GAS, Rojas M: Activation of apoptosis, but not necrosis, during Mycobacterium tuberculosis infection correlated with decreased bacterial growth: role of TNF-alpha, IL-10, caspases and phospholipase A2. Cell Immunol 2007, 249:80-93.

16. Cowley SC, Elkins KL: CD4+ T cells mediate IFN-gamma-independent control of Mycobacterium tuberculosis infection both in vitro and in vivo. J Immunol 2003, 171:4689-4699.

17. Sytwu HK, Liblau RS, McDevitt HO: The roles of Fas/APO-1 (CD95) and TNF in antigen-induced programmed cell death in T cell receptor transgenic mice. Immunity 1996, 5:17-30.

18. Wong B, Choi Y: Pathways leading to cell death in T cells. Curr Opin Immunol 1997, 9:358-364
19. Mrugacz M: Fas expression in conjunctival epithelial cells of patients with cystic fibrosis. J Interferon Cytokine Res 2009, 29:735-740.

20. Zhong J, Gilbertson B, Cheers C: Apoptosis of CD4+ and CD8+ T cells during experimental infection with Mycobacterium avium is controlled by Fas/FasL and Bcl-2-sensitive pathways, respectively. Immunol Cell Biol 2003, 81:480-486.

21. CDC: Case definitions for infectious conditions under public health surveillance. MMWR 1997, 46:40-41.

22. Nastasi A, Mammina C: Epidemiological study of tuberculosis in Palermo, Italy: IS6110 fingerprinting of Mycobacterium tuberculosis strains isolated in the years 1994-1998. Infection 1999, 27:318-222.

23. Saporito L, Florena AM, Colomba C, Pampinella D, Di Carlo P: Prurigo nodularis due to Mycobacterium tuberculosis. J Med Microbiol 2009 58:1649-1651.

24. American Thoracic Society: Treatment of tuberculosis and tuberculosis infection in adults and children. Am J Respir Crit Care Med 1994, 149:1359-1374.

25. Di Carlo P, Romano A, Melis M, Abbagnato L, Caccamo N, Meraviglia S, Dieli F: An overview of the role of T cells in controlling tuberculosis infection in a pediatric population. J Ped Infect Dis 2009, 4:221-228.

26. Melis MR, Pace E, Di Carlo P, Romano A, Titone L, Vignola AM, Ferraro M, Tipa A, Bonsignore G, Gjomarkai M: Increased peripheral T-Lymphocyte apoptosis in Childhood tuberculosis. Am J Respir Crit Care Med 2002, 165:289, International Conference, Atlanta, Georgia. American Thoracic Society.

27. Pace $E$, Gjomarkaj M, Melis M, Profita M, Spatafora M, Vignola AM, Bonsignore G, Mody CH: Interleukin-8 induces lymphocyte chemotaxis into the pleural space. Role of pleural macrophages. Am J Respir Crit Care Med 1999, 159:1592-1599.

28. Tolomeo M, Di Carlo P, Abbadessa V, Titone L, Miceli S, Barbusca E, Cannizzo G, Mancuso S, Arista S, Scarlata F: Monocyte and Lymphocyte apoptosis resistance in acute and chronic brucellosis and its possible implications in Clinical Management. Clin Infect Dis 2003, 36:1533-1538.

29. Gallegos AM, van Heijst JW, Samstein M, Su X, Pamer EG, Glickman MS: A gamma interferon independent mechanism of CD4 T cell mediated control of M. tuberculosis infection in vivo. PLoS Pathog 2011, 7:e1002052.

30. Wu YE, Zhang SW, Peng WG, Li KS, Li K, Jiang JK, Lin JH: Changes in lymphocyte subsets in the peripheral blood of patients with active pulmonary tuberculosis. J Int Med Res 2009, 37:1742-1749.

31. Kapina MA, Shepelkova GS, Mischenko W, Sayles P, Bogacheva P, Winslow G, Apt AS, Lyadova IV: CD27low CD4 T lymphocytes that accumulate in the mouse lungs during mycobacterial infection differentiate from CD27high precursors in situ, produce IFN-gamma, and protect the host against tuberculosis infection. J Immunol 2007 178:976-985.

32. Winslow GM, Cooper A, Reiley W, Chatterjee M, Woodland DL: Early T-cell responses in tuberculosis immunity. Immunol Rev 2008, 225:284-299.

33. Vidal JE, de Oliveira AC, Hernández AV: CD4+ T-cell count and cerebrospinal fluid findings in HIV-infected patients with tuberculous meningitis. Int J Tuberc Lung Dis 2010, 14:1496-1497.

34. Alexander-Miller MA, Leggatt GR, Sarin A, Berzofsky JA: Role of antigen, CD8, and cytotoxic T lymphocyte (CTL) avidity in high dose antigen induction of apoptosis of effector CTL. J Exp Med 1996, 184:485-492.

35. Thoma-Uszynski S, Stenger S, Modlin R: CTL-Mediated Killing of Intracellular Mycobacterium tuberculosis Is Independent of Target Cell Nuclear Apoptosis. J Immunol 2000, 165:5773-5779.

36. $Y u T$, Yang $Y H$, Dong DQ: The role of $C D 8+C D 28$-regulatory $T$ lymphocytes in pulmonary tuberculosis. Zhonghua Jie He He Hu Xi Za Zhi 2007, 30:130-132.

37. Yang $Y$, Tang SJ, Zhang Q, Sun H, Liu YD, Hao XH, Yao L, Gu J: The changes and the significance of cellular immune function in peripheral blood of patients with multidrug-resistant and extensively drug-resistant pulmonary tuberculosis. Zhonghua Jie He He Hu Xi Za Zhi 2011, 34:109-113.

\section{Pre-publication history}

The pre-publication history for this paper can be accessed here: http://www.biomedcentral.com/1471-2431/11/108/prepub

doi:10.1186/1471-2431-11-108

Cite this article as: Carlo et al:: Lymphocyte apoptosis in children with central nervous system tuberculosis: a case control study. BMC Pediatrics 2011 11:108. 